\title{
KINETIKA PENGERINGAN TEMU HITAM (Curcuma aeruginosa Roxb.) MENGGUNAKAN CABINET DRYER DENGAN PERLAKUAN PENDAHULUAN BLANCHING
}

\author{
DRYING KINETICS OF TEMU HITAM (Curcuma aeruginosa Roxb.) USING A CABINET \\ DRYER WITH THE BLANCHING PRETREATMENT
}

\author{
Baskoro Aji Sujarwo ${ }^{1)}$, Bambang Sigit Amanto ${ }^{1)}$ dan Siswanti' ${ }^{1)}$, \\ Program Studi Ilmu dan Teknologi Pangan, Fakultas Pertanian, Universitas Sebelas Maret
}

Email: baskoroaji19@gmail.com

\begin{abstract}
(Curcuma aeruginosa Roxb.) is one herb that has many benefits. The purpose of this study was to determine a preliminary blanching process and also use dryer temperature variations can be affect the drying kinetics, quality product temu hitam, And also the efficiency of the cabinet dryer.From this research we known that the temperature variation of the drying process and blanching treatment on Temu Hitam can be Effect drying kinetics. The results showed that the using higher the temperature of drying can be speed up the drying process to a safe moisture content limit simplicia product is $\leq 10 \%$. Quality of product Temu Hitam Showed that the use temperatur variation of the drying process can reach the standard of the water content maksimum simplicia Temu hitam. For best kukumin levels of $8.38 \%$ on the use of dryer temperature of $50^{\circ} \mathrm{C}$. This indicates that the use of high drying temperature can be affects the content of the active substance in the material.
\end{abstract}

Keywords : Temu Hitam, Blanching, kurkumin, Drying Kinetics, cabinet dryer

\section{ABSTRAK}

Temu Hitam (Curcuma aeruginosa Roxb.) merupakan salah satu tanaman herbal yang memiliki banyak khasiat. Tujuan dari penelitian ini untuk mengetahui proses pendahuluan berupa blanching dan juga penggunaan variasi suhu pengering dapat berpengaruh terhadap kinetika pengeringan, kualitas mutu produk simplisia temu hitam dan juga efisiensi alat pengering cabinet dryer. Dari penelitian ini diketahui bahwa perlakuan suhu dan perlakuan pendahuluan blanching terhadap simplisia Temu hitam berpengaruh terhadap kinetika pengeringan. Hasil menunjukkan bahwa semakin tinggi suhu pengeringan maka semakin cepat juga pengeringan berlangsung sampai dengan batas kadar air aman produk simplisia yaitu $\leq 10 \%$. Kualitas mutu produk simplisia temu hitam menunjukkan bahwa penggunaan masing - masing suhu telah memenuhi standar kadar air maksimum simplisia. Untuk kadar kurkumin terbaik sebesar $8,48 \%$ pada penggunaan suhu pengering $50^{\circ} \mathrm{C}$ hal ini menunjukkan penggunaan suhu tinggi pada proses pengeringan dapat mempengaruhi kandungan kurkumin dalam temu hitam.

Kata kunci : Temu Hitam, Blanching, Kurkumin, Kinetika Pengeringan, cabinet dryer

\section{PENDAHULUAN}

Tumbuhan obat Indonesia banyak dimanfaatkan sebagai obat tradisional Indonesia diantaranya: sebagai jamu, obat herbal terstandar, dan fitofarmaka. Berbagai penelitian dan pengembangan yang memanfaatkan kemajuan teknologi sebagai usaha peningkatan mutu dan keamanan produk yang diharapkan dapat lebih meningkatkan kepercayaan terhadap manfaat obat bahan alam. Selain itu, juga sebagai usaha meningkatkan status obat tradisional menjadi fitofarmaka. Sediaan dibuat dalam bentuk ekstrak atau fraksi yang terstandar dan memenuhi persyaratan jaminan kualitas, jaminan keamanan dan jaminan manfaat (Badan POM RI, 2005).
Indonesia dikenal dari dulu dalam obat jamu tradisionalnya. Sebagian besar simplisia yang digunakan untuk obat tradisional berasal dari famili Zingiberaceae, dan salah satu tanaman obat dari famili Zingiberaceae adalah temu ireng. Karena khasiatnya sebagai obat, maka tanaman temu ireng sudah dikenal cukup luas di Indonesia dengan nama daerah yang berbeda-beda seperti: temu hitam (Indonesia), temu ireng (jawa), koneng hideung (Sunda), temu erang (Sumatra), temu ereng (Madura). Di negara Asia lainnya seperti Malaysia, Burma, Kamboja, dan Indonesia tanaman ini sudah dikenal sebagai tanaman obat, bahkan sudah dibudidayakan secara besar-besaran (Djauhariyah; Siti, 2001).

Menurut data Badan Pusat Statistik (BPS 2012) produksi tanaman obat temu 
hitam pada tahun 2012 sebesar $61.127 \mathrm{~kg}$. Data tersebut menggambarkan betapa potensialnya temu hitam untuk dijadikan tanaman obat terstandar yang memiliki banyak manfaat. Oleh karena itu dibutuhkan penelitian untuk dapat menghasilkan simplisia temuhitam yang masih mengandung senyawa aktif selama proses pengeringan simplisia.

Produk simplisia temu dibuat dengan melalui proses pengeringan. Untuk mendapatkan kandungan senyawa aktif yang bisa dimanfaatkan dalam produk dibutuhkan proses pengeringan yang tepat meliputi suhu dan waktu pengeringan untuk mendapatkan standar minimum kadar air yang terkandung dalam simplisia sebesar $10 \%$. Pada penelitian ini dilakukan perlakuan pendahuluan berupa proses blanching dalam penelitian ini bertujuan untuk menghambat reaksi pencoklatan yang terjadi pada saat dan setelah proses pengeringan. Penelitian ini juga menggunakan tiga variasi suhu pengeringan bertujuan untuk mengetahui kandungan senyawa aktif yang tersisa dalam bahan setelah proses pengeringan. Selama proses pengeringan simplisia temu hitam diamati pula kinetika pengeringan simplisia yang meliputi penurunan laju pengeringan, lama proses pengeringan, dan juga moisture content dari produk simplisia temu hitam untuk dapat menganalisa proses pengeringan. Dengan adanya pengamatan tersebut dapat diketahui berapa energi alat pengering yang dibutuhkan untuk dapat mengeringkan produk hingga menjadi produk simplisia temu hitam.

\section{METODE PENELITIAN}

\section{Bahan dan Alat}

Bahan utama yang digunakan selama penelitian ini yaitu rimpang temu hitam yang berasal dari Wonogiri, namun di distribusikan oleh pedagang yang terletak di pasar Legi, Solo. Temu hitam di slicer secara manual dengan ketebalan $3 \mathrm{~mm}$ yang dikeringkan menggunakan cabinet dryer. Selain itu digunakan aquades sebagai bahan dalam proses blanching.

Alat yang digunakan dalam penelitian ini adalah slicer manual, cabinet dryer, blender, , thermometer, hygrometer timbangan analitik "Ohaus, Adventurer" AR2140", botol timbang, oven "Memmert", desikator "Iwaki", chromameter "Konika minolta 400", erlenmeyer,labu ukur, spektrofotometer UV-Vis "Shimadzu, UVMini 1240".

\section{Tahapan Penelitian}

Tahapan penelitian meliputi persiapan bahan, pencucian temu hitam, pengirisan temu hitam, proses blanching, pengeringan temu hitam, perhitungan penurunan kadar air, pencatatan kelembaban relatif, analisis data.

\section{HASIL DAN PEMBAHASAN}

\section{Kinetika Pengeringan \\ 1. Laju pengeringan selama proses pengeringan}

Menurut Muchtadi dan Fitriyono (2010), Umumnya semakin besar perbedaan suhu antara medium pemanas dengan bahan pangan, semakin cepat pemindahan panas ke dalam bahan dan semakin cepat pula di penghilangan air dari bahan. Apabila udara merupakan medium pemanas, maka suhu hanya merupakan faktor penting yang kedua. Karena air yang keluar dari bahan pangan berupa uap air, maka uap air tersebut harus dikeluarkan dari udara tersebut, sebab bila tidak uap air tersebut akan memenuhi atmosfer di sekeliling permukaan bahan sehingga akan memperlambat penyerapan selanjutnya. Makin tinggi suhu udara makin banyak uap air yang dapat ditampung sebelum terjadi kejenuhan, jadi, udara yang bersuhu tinggi yang digunakan dalam pengeringan bahan pangan akan mengambil lebih banyak uap air dari bahan dibandingkan dengan udara dingin. Makin besar volume udara, juga dapat mengambil lebih banyak uap air. Kekeringan (kelembaban) udara juga menentukan sampai kadar air beberapa bahan pangan dapat dikeringkan. Bahan pangan kering bersifat higroskopis. 

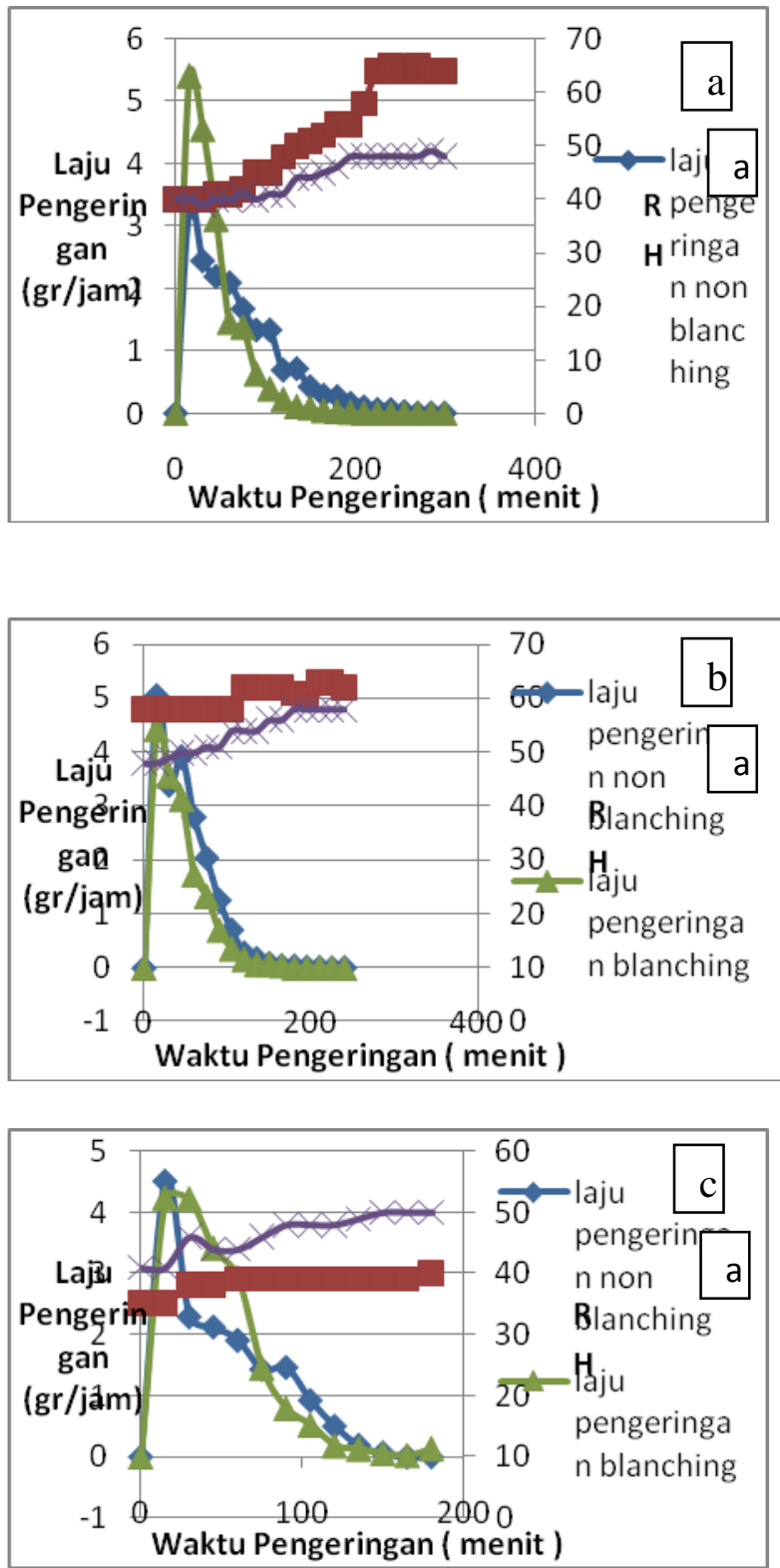

Gambar 1. Grafik hubungan laju pengeringan dan RH terhadap waktu pengeringan: (a) suhu $50^{\circ} \mathrm{C}$, (b) suhu $60^{\circ} \mathrm{C}$ dan (c) suhu $70^{\circ} \mathrm{C}$.

\section{Kadar Air selama Pengeringan}

Menurut Muchtadi dan Fitriyono (2010), Kadar air pada permukaan bahan dipengaruhi oleh kelembaban nisbi RH udara disekitarnya. Bila kadar air bahan rendah sedangkan RH disekitarnya tinggi, maka akan terjadi penyerapan uap air dari udara sehingga bahan menjadi basah atau kadar airnya menjadi tinggi. Bila suhu bahan lebih rendah akan terjadi kondensasi udara pada permukaan bahan dan dapat merupakan media yang baik bagi perkembangbiakan bakteri atau pertumbuhan kapang.

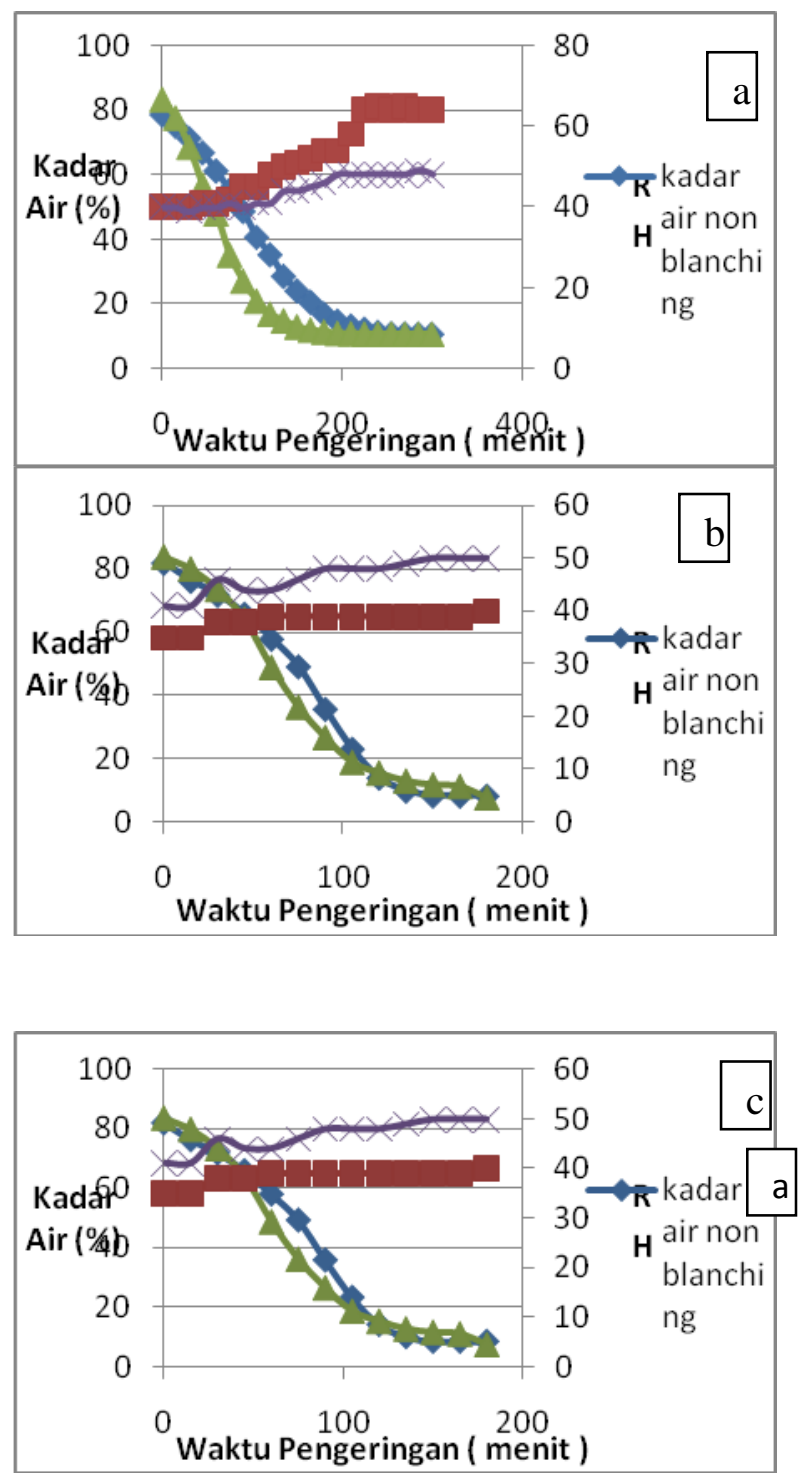

Gambar 2. Penurunan Kadar Air: (a) suhu $50^{\circ} \mathrm{C}$, (b) suhu $60^{\circ} \mathrm{C}$ dan (c) suhu $70^{\circ} \mathrm{C}$.

Dalam proses pengeringan menurut Gaman dan Sherington (1992) yang dikutip oleh Fitriani (2008), hal yang paling penting adalah suhu yang digunakan tidak terlalu tinggi, karena akan mengakibatkan perubaan - perubahan yang tidak dikehendaki pada bahan pangan. Jika suhu yang digunakan terlalu tinggi akan mengakibatkan case hardening yaitu suatu keadaan bagian luar bahan menjadi keriput dan keras, sedangkan air terperangkap di dalamnya. Air ini tidak bisa menerobos bahan dalam difusi yang normal.

\section{Kebutuhan Energi}

Efisiensi pengeringan merupakan perbandingan panas teoritis yang dibutuhkan untuk menghasilkan panas laten yang 
digunakan untuk menguapkan air dalam bahan yang dikeringkan dengan menggunakan panas sebenarnya dalam alat pengering. Semakin tinggi nilai efisiensi alat maka semakin bagu proses pengeringan itu berlangsung. Pada Tabel diatas menunjukkan efisiensi pengering cabinet dryer, efisiensi paling tinggi pada perlakuan non blanching yaitu pada suhu $70^{\circ} \mathrm{C}$ sebesar 5,421\%. Sedangkan untuk perlakuan blanching efisiensi pengering tertinggi pada suhu $70^{\circ} \mathrm{C}$ sebesar $5,558 \%$.

Tabel 1 . Kebutuhan Energi pada Berbagai Suhu

Perlakuan Efisiensi Pengering

$\begin{array}{cc}50^{\circ} \mathrm{C} \text { non blanching } & 2,966 \\ 60^{\circ} \mathrm{C} \text { non blanching } & 3,916 \\ 70^{\circ} \mathrm{C} \text { non blanching } & 5,421 \\ 50^{\circ} \mathrm{C} \text { blanching } & 3,102 \\ 60^{\circ} \mathrm{C} \text { blanching } & 4,028 \\ 70^{\circ} \mathrm{C} \text { blanching } & 5,558\end{array}$

Kualitas Mutu Produk Simplisia Temu Hitam

\section{Kadar Air}

Tabel 2 . Kadar Air Simplisia Temu Hitam

\begin{tabular}{lll}
\hline Suhu & \multicolumn{2}{l}{$\begin{array}{l}\text { Produk simplisia } \\
\text { Non } \\
\text { blanching }\end{array}$} \\
\hline $50^{\circ} \mathrm{C}$ & $10,67^{\mathrm{aA}}$ & $10,69^{\mathrm{aA}}$ \\
$60^{\circ} \mathrm{C}$ & $8,66^{\mathrm{bA}}$ & $8,77^{\mathrm{bA}}$ \\
$70^{\circ} \mathrm{C}$ & $8,26^{\mathrm{bA}}$ & $7,36^{\mathrm{bA}}$ \\
\hline
\end{tabular}

Menurut John M (1997) Karena pentingnya air sebagai komponen makanan diperlukan pemahaman mengenai sifat dan perilakunya. Adanya air mempegaruhi kemerosotan mutu makanan secara kimia dan mikrobiologi. Begitu pula, penghilangan (pengeringan) atau pembekuan air penting pada beberapa proses pengawetan makanan. Pada kedua peristiwa itu perubahan yang mendasar dalam produk dapat terjadi. Pada Tabel 2 menunjukan bahwa penggunaan suhu pengering $50^{\circ} \mathrm{C}$ memberikan efek berbeda nyata terhadap kadar air pada taraf signifikansi $\alpha<0,05$ sedangkan perlakuan pendahuluan berupa blanching terhadap kadar air tidak memberikan efek yang berbeda nyata terhadap kadarair temu hitam.

\section{Kadar Kurkumin Simplisia Temu Hitam}

Menurut (Istafid, 2006 dalam

Kiswanto, 2009) yang dikutip dalam skripsi (Oktaviana, 2010). Kurkuminoid merupakan unsur non zat gizi yang mempunyai sifat atau karakteristik yaitu senyawa khas dari kurkumin (flavour) yang berwarna kuning dan bersifat aromatik, terdiri dari campuran kurkumin, desmetoksikurkumin, dan bidesmetoksikurkumin sehingga apabila digunakan dalam makanan atau minuman dapat berfungsi sebagai pewarna makanan atau minuman yaitu memberikan warna kuning sekaligus aroma, bau dan rasa khas pada makanan dan minuman. Sedangkan dalam bidang kesehatan, kurkuminoid bermanfaat sebagai senyawa antioksidan yang dapat menangkal atau melokalisir radikal bebas (karsinogenik) akibat mengkonsumsi makanan yang kurang sehat, sehingga kurkuminoid mempunyai efek antirematik dalam pengobatan secara tradisional.

Tabel 3 . Kadar Kurkumin Simplisia Temu Hitam

\begin{tabular}{ccc}
\hline Suhu & \multicolumn{2}{c}{ Produk simplisia } \\
& $\begin{array}{c}\text { Non } \\
\text { blanching }\end{array}$ & \\
\hline $50^{\circ} \mathrm{C}$ & $8,48^{\mathrm{aA}}$ & $8,17^{\mathrm{aB}}$ \\
$60^{0} \mathrm{C}$ & $7,90^{\mathrm{bA}}$ & $7,65^{\mathrm{bB}}$ \\
$70^{0} \mathrm{C}$ & $6,93^{\mathrm{cA}}$ & $6,49^{\mathrm{cB}}$ \\
\hline
\end{tabular}

Hasil penelitian menunjukkan bahwa penggunaan suhu pengering $50^{\circ}, 60^{\circ}$, dan $70^{\circ}$ memberikan efek yang berbeda nyata terhadap kadar kurkumin temu hitam pada taraf signifikansi $\alpha<0,05$ dan juga pada perlakuan pendahuluan berupa blanching memberikan efek yang berbeda nyata terhadap kadar kurkumin.

Menurut Rusli dan Darmawan (1988) bahwa pengeringan suatu bahan terlalu lama dan suhunya yang terlalu tinggi dapat menurunkan mutu karena dapat merusak komponen-komponen yang terdapat di dalamnya Dari tabel di atas dapat dikatakan sesuai dengan sumber terdahulu, pada suhu 
pengering $50 \quad{ }^{0} \mathrm{C} \quad$ kandungan kurkumin simplisia temu hitam lebih besar dibandingkan suhu pengering $60{ }^{\circ} \mathrm{C}$ dan 70 ${ }^{0} \mathrm{C}$. Sedangkan untuk suhu pengering $70{ }^{0} \mathrm{C}$ menghasilkan produk simplisia temu hitam dengan kandungan kurkumin terkecil. Hal ini disebabkan kurkumin rentan akan pengaruh panas yang berlebih pada proses blanching.

\section{Uji Warna Produk Simplisia Temu Hitam}

Menurut Herliani (2008), Warna bahan pangan tergantung pada kenampakan bahan pangan tersebut dan kemampuan untuk memantulkan, menyebarkan, menyerap atau meneruskan sinar tampak. Bahan pangan dalam bentuk aslinya biasanya berwarna terang. Pengeringan bahan pangan akan mengubah sifat - sifat fisik dan kimia. Kerotenoid akan berubah selama proses pengeringan, makin tinggi suhu dan lama waktu pengeringan makin banyak zat warna yang berubah.

Tabel 4. Nilai L* Simplisia Temu Hitam

\begin{tabular}{lll}
\hline Suhu & \multicolumn{2}{l}{ Produk simplisia } \\
& $\begin{array}{l}\text { Non } \\
\text { blanching }\end{array}$ & \\
\hline $50^{\circ} \mathrm{C}$ & $68,91^{\mathrm{aA}}$ & $61,59^{\mathrm{aB}}$ \\
$60^{\circ} \mathrm{C}$ & $68,55^{\mathrm{aA}}$ & $62,47^{\mathrm{aB}}$ \\
$70^{0} \mathrm{C}$ & $69,15^{\mathrm{aA}}$ & $62^{\mathrm{aB}}$ \\
\hline
\end{tabular}

Tabel 5. Nilai a* Simplisia Temu Hitam

\begin{tabular}{|c|c|c|}
\hline \multirow[t]{2}{*}{ Suhu } & \multicolumn{2}{|c|}{ Produk simplisia } \\
\hline & $\begin{array}{l}\text { Non } \\
\text { blanching }\end{array}$ & Blanching \\
\hline $50^{\circ} \mathrm{C}$ & $0,79^{\mathrm{aA}}$ & $2.22^{\mathrm{aB}}$ \\
\hline $60^{\circ} \mathrm{C}$ & $0,90^{\mathrm{aA}}$ & $2,18^{\mathrm{aB}}$ \\
\hline $70^{\circ} \mathrm{C}$ & $2,54^{\mathrm{bA}}$ & $2,26^{\mathrm{aB}}$ \\
\hline
\end{tabular}

Tabel 6. Nilai b* Simplisia Temu Hitam

\begin{tabular}{lll}
\hline Suhu & \multicolumn{2}{l}{ Produk simplisia } \\
& $\begin{array}{l}\text { Non } \\
\text { blanching }\end{array}$ & Blanching \\
\hline $50^{\circ} \mathrm{C}$ & $20,07^{\mathrm{aA}}$ & $19,39^{\mathrm{aB}}$ \\
$60^{\circ} \mathrm{C}$ & $18,81^{\mathrm{bA}}$ & $18,59^{\mathrm{aB}}$ \\
$70^{\circ} \mathrm{C}$ & $17,14^{\mathrm{cA}}$ & $16,40^{\mathrm{bB}}$ \\
\hline
\end{tabular}

Pengujian warna dengan menggunakan kromameter menggunakan sistem notasi Hunter dengan tiga dimensi warna $L^{*}, a^{*}, b^{*}$. Nilai $L^{*}$ menyatakan tingkat kecerahan dengan nilai dari 0 (gelap) sampai 100 (putih), sehingga semakin besar nilai $\mathrm{L}^{*}$ maka kecerahannya semakin tingggi. Nilai a* (redness) menyatakan warna merah dan hijau dengan nilai $a^{*}$ positif dari 0 sampai 100 menunjukan warna merah sedangkan nilai $a^{*}$ negatif dari 0 sampai -80 menunjukkan intensitas warna hijau. Nilai b* (yellowness) menyatakan warna campuran biru dan kuning dengan nilai $b^{*}$ positif dari 0 sampai +70 menunjukkan warna kuning sedangkan nilai $\mathrm{b}^{*}$ negatif dari 0 sampai -70 menunjukkan intensitas warna biru.

Nilai $b^{*}$ (yellowness) merupakan nilai yang meyatakan campuran warna biru dan kuning nilai $b^{*}$ positif menunjukkan kecenderungan bahan berwarna kuning. Dari hasil analisa dapat disimpulkan bahwa nilai $b^{*}$ tertinggi pada rimpang temu hitam didapat pada saat proses pengeringan $50^{\circ} \mathrm{C}$ dan nilai $\mathrm{b}^{*}$ terendah pada saat proses pengeringan $70^{\circ}$ C. Nilai $b^{*}$ yang didapat pada penelitian ini berkolerasi dengan nilai kurkumin yang terkandung dalam bahan, semakin rendah suhu yang digunakan maka semakin tinggi pula nilai kurkumin yang di dapat. Dapat disimpulkan bahwa intensitas warna kuning yang terdapat dalam bahan mempengaruhi kandungan kurkumin yang terdapat dalam rimpang temu hitam.

\section{KESIMPULAN}

Kesimpulan dari penelitian ini adalah sebagai berikut :

1. Pada penelitian ini perlakuan pendahuluan berupa blanching tidak memberikan pengaruh yang beda nyata terhadap parameter kadar air namun memberikan pengaruh yang beda nyata terhadap kandungan kurkumin dan parameter warna dalam temu hitam.

2. Kadar air produk telah memenuhi standar kadar air simplisia. Untuk kadar air terendah pada suhu pengering $70^{\circ} \mathrm{C}$ pada perlakuan blanching sebesar 7,36\%. Kadar kurkumin tertinggi pada suhu pengering $50^{\circ} \mathrm{C}$ pada perlakuan non blanching sebesar 8,48 \%. Sedangkan untuk parameter warna kuning, pada pengujian warna tertinggi pada suhu pengering $50^{\circ} \mathrm{C}$ perlakuan non 
blanching sebesar 20,07 . Efisiensi pengering tertinggi pada perlakuan non blanching pada suhu pengering $70^{\circ} \mathrm{C}$ sebesar 5,56\%.

\section{DAFTAR PUSTAKA}

Badan Pusat Statistik Indonesia (BPS). Produksi Tanaman Herbal Obat Indonesia. Diakses pada hari Rabu 5 Maret 2014 pkl 10.30 WIB.

Badan Pengawas Obat dan Makanan RI. Khasiat Tanaman Rimpang. Diakses pada Hari Rabu 5 Maret 2014 pkl 10.45 WIB.

Djauhariyah dan Siti, 2011. Khasiat Tanaman Obat Indonesia. UNS Press. 2011. Surakarta.

Fitriani, Shanti. 2008. Pengaruh Suhu dan Lama Pengeringan Terhadap Beberapa Mutu Manisan Belimbing Waluh Kering. Vol 7. No. 1. Hal. 32 - 37.

Herliani, Leni. 2008. Teknologi Pengawetan Pangan. Alfabeta. Bandung.

Istafid, widi. 2006. Visibility studi minuman instan Ekstrak temulawak dan ekstrak mengkudu Sebagai minuman kesehatan. Skripsi. UNNES. Semarang.

John. 1997. Kimia Makanan. Penerbit ITB. Bandung.

Kiswanto. 2005. Perubahan kadar senyawa bioaktif Rimpang temulawak dalampenyimpanan (Curcuma xanthorrhiza Roxb). Fakultas Teknologi Pertanian Institut Pertanian (INTAN). Yogyakarta.

Muchtadi, Tien; Fitriyono. 2010. Teknologi Proses Pengolahan Pangan. Alfabeta. Bandung.

Rosdiana. 2014. Kinetika Pengeringan Chips Sukun ( Artocarpus communis) Dalam Pembuatan Tepung Sukun Termodifikasi Dengan Asam Laktat Menggunakan Cbinet Dryer. Skripsi. Universitas Sebelas Maret Surakarta. 